\title{
Splenektomi yapılan hastaların aşılanmalarının ve bu konudaki bilgilerinin değerlendirilmesi
}

\author{
An evaluation of immunization practices and their knowledge about this issue in splenectomized \\ patients
}

Mehmet ULUĞ, Vahap ASLAN, Namık YILMAZ, İbrahim DOLU

\section{ÖZET}

Amaç: Dalak hem hümoral ve hem de hücresel bağışılklıta görev alan bir organdır. Bu nedenle organizmayı enfeksiyonlara karşı korumada önemli fonksiyonları vardır. Bu çalışmada, splenektomi yapılmış hastaların aşılanma öyküleri ve bu konudaki bilgi düzeylerinin değerlendirilmesi amaçlanmıştır.

Hastalar ve Yöntem: Bu çalışmada, Mart 2010-Ekim 2013 tarihleri arasında hastanemiz ve/veya hastanemiz dişında splenektomi yapılıp da hastanemiz Enfeksiyon Hastalıkları, Hematoloji ve Genel Cerrahi polikliniklerine başvuran 51 hastanın verileri değerlendirilmiştir.

Bulgular: Hastaların 26's1 $(\% 50,9)$ kadın ve 25'i $(\% 49,1)$ erkek olup, yaş ortalaması 53,3 yıl (yaş aralığı, 21-83 yıl) idi. Splenektomi nedenleri incelendiğinde en sik idiyopatik trombositopenik purpura $(n=23, \% 45)$, tümör metastazı $(n=8$, $\% 15,7)$ ve otoimmün hemolitik anemi $(n=7, \% 13,7)$ tespit edildi. Pnömokok aşısı, hastaların \%64'üne operasyon öncesi, \%23'üne operasyon sonrası uygulanmışken \%13'üne $(n=7)$ hiç uygulanmadığı saptandı. Diğer merkezlerden gelen yedi hastaya aşılanma konusunda hekimlerince hiç bilgi verilmediği saptanırken, diğer yedi hasta sadece pnömokok aşısı hakkında bilgilendirilmekle birlikte bilgilerin ve uygulama süreçlerinin hatalı olduğu saptand.

Sonuç: Çalışmamızda görüldüğü gibi, splenektomi yapılmış hastalara, yalnızca değişen sıklıkta pnömokok aşısı uygulandığı ve diğer aşılar hakkında bilgilendirme yapılmadı $\breve{g} 1$ belirlenmiştir. Bu durum, hem konu ile ilgili sağlık çalışanlarının ve hem de hastaların bilgi düzeylerinin yeterli olmadığını, bu neden ile, erişkin aşılamada multidisipliner çalışmaların gerekliliğini ortaya koymaktadır.

Anahtar kelimeler: Erişkin aşılaması, Pnömokok aşısı, Splenektomi

Mehmet ULUĞ (ه)

Enfeksiyon Hastallklarl ve Klinik Mikrobiyoloji, Özel Ümit Hastanesi, Eskişehir, Türkiye

e-mail: mehmetulug21@yahoo.com

Vahap ASLAN

Hematoloji, Özel Ümit Hastanesi, Eskişehir, Türkiye

Namık YILMAZ, İbrahim DOLU

Genel Cerrahi, Özel Ümit Hastanesi, Eskişehir, Türkiye

Gönderilme/Submitted: 30.05.2014 Kabul/Accepted: 03.09.2014

\begin{abstract}
Objectives: The spleen is an organ functional in both humoral and cellular immunity. Therefore, the spleen plays a major role in host defense against infections. In this study, we evaluated the immunization histories of splenectomized patients and their level of information on this subject.

Patients and Methods: A total of 51 patients who applied to Clinics of Infectious Diseases, Hematology and General Surgery from our hospital and from others and who had undergone splenectomy between March 2010 and October 2013 were enrolled.

Results: A total of $26(50.9 \%)$ patients were women and 25 (49.1\%) were men with a mean age 53.3 years (age range, 21-83 years). The most common reason for splenectomy was idiopathic thrombocytopenic purpura $(n=23,45 \%)$, followed by tumor metastasis $(n=8,15.6 \%)$ and autoimmune hemolytic anemia $(n=7$, $13.7 \%)$. Pneumococcal vaccination was done in $64 \%(n=32)$ of the patients before the operation, in $23 \%(n=12)$ after the operation while $13 \%(n=7)$ of the patients were not vaccinated. None of the seven patients from other hospitals were informed about vaccination by their doctors while information only about pneumococcal vaccination was given to the other seven patients, but there were errors in their vaccination procedures.

Conclusion: Immunization of patients undergoing splenectomy is frequently a forgotten and regarded as an unimportant topic. Usage of variable pneumococcal vaccination programs without giving any information to patients supports the view that both patients and clinicians have inadequate levels of information about vaccinations and shows the need for prompt multidisciplinary medical attention for adult patients.
\end{abstract}

Keywords: Adult vaccination, Pneumococcal vaccine, Splenectomy

\section{Giriș}

Erişkin bağışıklaması tüm dünyada olduğu gibi ülkemizde de güncel bir sorundur. Bu durum çocukluk dönemi aşı uygulamasındaki eksikliklerden ve bazı aşıların uzun süreli koruyuculuk sağlayamamasından kaynaklanmaktadır [1]. Yurtiçi ve yurtdışına yapılan seyahatler, bazı meslekler (sağlık çalışanları, veteriner hekimler, vb), yaşlılık, bağışıklık yetmezliği gibi değişik durumların getirdiği riskler belli aşıların erişkin döneminde de uygulanmasını 
zorunlu hale getirmektedir [2]. Bununla birlikte, aşılama ile hem ciddi komplikasyonları olan enfeksiyonlar önlenebilmekte ve hem de bu enfeksiyonların getireceği ek maliyet yükü azaltılabilmektedir [3].

Dalak hem humoral ve hem de hücresel bağışıklıkta görev alan bir organdır. Kan dolaşımındaki bakterilere karşı spesifik antikor yapılması, T ve B lenfositlerinin olgunlaştırılması, antikorla işaretli hücrelerin fagositozu, tuftsin ve properdin yapımı gibi immünolojik fonksiyonları vardır. Bununla birlikte, dalaktaki makrofaj ve histiyositler, antikor ya da opsonik proteinle işaretli bakterileri fagosite ederek ortadan kaldırırlar. Dolayısıyla dalağın, organizmayı enfeksiyonlara karşı korumada da önemli bir fonksiyonu vardır [4,5]. Bu nedenle de splenektomi yapılan hastalarda gelişebilecek enfeksiyonlar, etkin aşılanma ile önlenebilmektedir.

$\mathrm{Bu}$ çalışmada, splenektomi yapılmış erişkin hastaların aşılanma öyküleri ve bu konudaki bilgi düzeylerinin araştırılması, aşılanma konusunda hastaların bilgilendirilmesi ve eksik olan aşılarının tamamlanması amaçlanmıştır.

\section{Hastalar ve Yöntem}

Bu çalışmada, Mart 2010-Ekim 2013 tarihleri arasında hastanemiz ve/veya hastanemiz dışında splenektomi yapılıp da hastanemiz Enfeksiyon Hastalıkları, Hematoloji ve Genel Cerrahi polikliniklerine başvuran 51 hastanın verileri değerlendirilmiştir.

Çalışmamız tanımlayıcı nitelikte olup, veri toplama aracı olarak demografik bilgiler ile olguların aşılanma hakkındaki bilgi, tutum ve davranışlarını değerlendirme amacına uygun olarak hazırlanmış 16 soru içeren bir anket kullanılmıştır. Araştırma Helsinki Deklarasyonu'na uygun olarak yapılmış olup hastanemiz Etik Kurulu onayı alınarak planlanmıştır. Anket çalışması, Enfeksiyon Hastalıkları Uzmanı tarafından birebir yüz yüze görüşme tekniği ile gerçekleştirilmiştir.

Araştırmamız sonucunda elde edilen veriler bilgisayar ortamına aktarılmış ve SPSS 15.0 programına girilmiştir. Tanımlayıcı analizlerde ortalama ve standart sapma kullanılmıştır.

\section{Bulgular}

Çalışma kapsamında değerlendirilen hastaların 37'sine $(\% 72,6)$ hastanemizde, 14 'üne $(\% 27,4)$ ise dış merkezlerde (12 hasta devlet hastaneleri ve iki hasta üniversite hastanesi) splenektomi yapılmıştır. Bu hastaların 26'sı $(\% 50,9)$ kadın ve 25 'i $(\% 49,1)$ erkek olup, yaş ortalaması 53,3 yıl (yaş aralığ $1,21-83$ yıl) idi. Hastaların eğitim durumları araştırıldığında bir hastanın (\%2) okur-yazar olmadığı, altısının $(\% 11,8)$ ilköğretim, 12 'sinin $(\% 23,5)$ üniversite ve
Tablo I: Hastaların splenektomi nedenleri

\begin{tabular}{lrr}
\hline & n & $\mathbf{( \% )}$ \\
\hline İdiyopatik trombositopenik purpura & 23 & $(45)$ \\
Tümör metastazı & 8 & $(15,7)$ \\
Otoimmün hemolitik anemi & 7 & $(13,7)$ \\
Travma & 3 & $(5,9)$ \\
Herediter sferositoz & 3 & $(5,9)$ \\
Non-Hodgkin lenfoma & 3 & $(5,9)$ \\
Dalak kisti & 2 & $(3,9)$ \\
Apse & 1 & $(2)$ \\
Kist hidatik & 1 & $(2)$ \\
\hline
\end{tabular}

32 'sinin $(\% 62,7)$ ise lise mezunu olduğu saptandı. Bununla birlikte, hastaların splenektomi nedenleri incelendiğinde, en s1k idiyopatik trombositopenik purpura (ITP) $(n=23, \% 45)$, tümör metastazı $(\mathrm{n}=8, \% 15,6)$ ve otoimmün hemolitik anemi ( $\mathrm{n}=7, \% 13,7)$ olduğu tespit edildi (Tablo I).

Hastaların, erişkin dönemde uygulanan aşılar hakkındaki bilgileri değerlendirildiğinde 27 hasta $(\% 52,9)$ erişkin aşılarından haberdar olduğunu, 22 hasta $(\% 43,1)$ erişkin aşılarının varlığından bilgisinin olduğunu ancak bu aşıların sadece hasta olanlara yapılması gerektiğini ve iki hasta $(\% 3,8)$ aşıların sadece çocuklar için gerekli olduğunu belirtmiştir. Hastalar tarafından en fazla bilinen erişkin aşısı sıklık sırasına göre mevsimsel grip $(\mathrm{n}=41, \% 80,4)$, tetanoz $(\mathrm{n}=26, \% 50,9)$, hepatit $\mathrm{B}(\mathrm{n}=16, \% 31,3)$ ve kuduz aş1s1 $(n=9, \% 17,6)$ olduğu belirlenmiştir. Olguların erişkin aşıları konusunda bilgi edindikleri kaynaklar incelendiğinde ise sıklık sırasına göre aile hekimi/ilgili doktoru $(\mathrm{n}=32, \% 62,7)$, ailesi ve/veya arkadaşları $(\mathrm{n}=27, \% 52,9)$, televizyon/internet $(\mathrm{n}=17, \% 33,3)$ ve gazete/dergi $(\mathrm{n}=7, \% 13,7)$ olduğu görülmüştür.

Hastaların, 44'ünün $(\% 86,3)$ splenektomi öncesi ve sonrasında aşılanmaları gerektiği konusunda bilgilerinin olduğu tespit edilmiştir. Bu olgulara aşılama hakkındaki bilgilerin ilgili hekimleri tarafından verildiği belirlenmiştir. Pnömokok aşısının olguların \%62,7'sine $(n=32)$ operasyon öncesi, \%23,5'ine ( $\mathrm{n}=12)$ operasyon sonrası uygulanmışken $\% 13,7$ 'sine $(\mathrm{n}=7)$ hiç uygulanmadığı saptanmıştır. Diğer merkezlerden gelen 14 hastadan, yedi hastaya aşılanma konusunda hekimlerince hiç bilgi verilmediği belirlenirken, diğer yedi hasta sadece pnömokok aşısı hakkında bilgilendirilmekle birlikte, bilgilerin ve uygulama süreçlerinin hatalı olduğu tespit edilmiştir. Olguların 14'üne $(\% 27,4)$ pnömokok aşısı dışındaki aşılarla (Hemophilus influenzae tip B konjuge aşı1, Neisseria meningitis, mevsimsel grip, hepatit B ve tetanoz aşıları) ilgili hiç bilgilendirme yapılmadığı ve olguların bu aşılardan herhangi birini yaptırmadığ 1 saptanmıştır. Bununla birlikte, hiç aşılanmayan yedi olgudan 
ikisinin $(\mathrm{n}=2 / 7, \% 28,5)$ splenektomi sonrasinda pnömoni nedeniyle hastanede yattıkları öğrenilmiştir.

\section{Tartıșma}

Erişkinler ve özellikle splenektomili hastaların yer aldığ 1 riskli grupların aşılanması çoğu zaman önem verilmeyen veya unutulan bir konudur. Splenektomili hastalarda gelişen septik komplikasyonların, dalak fonksiyonlarının kaybı ile gelişen çok sayıda immünolojik değişikliklerden kaynaklandığ 1 gösterilmiştir. Bu değişiklikler arasında; immünoglobulin düzeylerinin değişmesi, komplemanın alternatif yolda aktivasyonunda azalma, serum opsonize edici proteinlerin kaybı ve hücresel immünitede ortaya çıkan değişiklikler sayılabilir [6,7]. Bu bağlamda, splenektomili hastalarda enfeksiyonlara karşı artmış bir duyarlılık olmasına rağmen aktif bağışıklanma hala istenen seviyeye ulaşamamıştır [8].

Yapılan çalışmalarda en sık splenektomi nedenleri irdelendiğinde; İTP, Girgin ve arkadaşlarının çalışmasında [5] olguların \%56'sında, Görkem ve arkadaşlarının çalışmasında [9] \%70,4'ünde en sık neden olarak saptanırken, Özkören ve arkadaşlarının çalışmasında [8] ise travma en sık neden olarak tespit edilmiştir. Bu çalışmada da İTP (\%45) en sık neden olarak belirlenmiştir. Splenektomi sonrası enfeksiyon gelişme riski altta yatan hastalıklara göre derecelendirilmiş olup travma düşük riskli olarak kabul edilmiştir. Herediter sferositoz, İTP ve portal hipertansiyon orta riskli iken malignite, talasemi ve Hodgkin hastalığı ise yüksek riskli olarak kabul edilmiştir [10,11].

Splenektomi sonrası artan enfeksiyon gelişimi riski, 1952 y1lında King ve Schumacker'in splenektomi yapılan infantlarda görülen ve hayatı tehdit eden enfeksiyonların ele alındığı beş olguluk çalışmasına kadar üzerinde çok fazla durulmamıştır [7,11]. Splenektomi sonrası gelişen enfeksiyon, gribal bir hastalık gibi başlayıp hızlıca septik şok veya disemine intravasküler koagülasyonun eşlik ettiği sepsis veya menenjit tablosuna ilerleyebilir. Bu durum, en sık splenektomi sonrası ilk iki yılda görülebildiği gibi daha sonraki yıllarda da görülebilir. Bu klinik tablonun gerçek sıklığı bilinmemekle birlikte, y1llık \%0,18-0,42, ömür boyu ise $\% 5$ olduğu tahmin edilmekte olup mortalite hızının da \%38-69 arasında olduğu düşünülmektedir. Splenektomi sonrası enfeksiyon gelişimi göreceli olarak daha çok genç erişkinlerde ve bir başka sağlık probleminin eşlik ettiği hastalarda izlenmektedir [12-14]. Bununla birlikte, splenektomi yapılan hastalarda uzun süreçte hastane kaynaklı enfeksiyon gelişimi riski de artmaktadır [15]. Splenektomi sonrası gelişen septisemi, menenjit ve pnömoni gibi ciddi enfeksiyon tablolarında hastalar mutlaka hastaneye yatırılarak takip ve tedavi edilmelidir. Bu çalışma kapsamında değerlendirilen iki olgunun da pnömoni nedeniyle hastanede yattıkları saptanmıştır.

Splenektomi sonrası gelişen ciddi enfeksiyonlarda başlıca etkenler kapsüllü bakteriler olup Streptococcus pneumoniae, $H$. influenzae tip B ve $N$. meningitis en s1k izole edilen patojenlerdir $[7,8,10,11]$. S. pneumoniae, polisakkarit yapısındaki kapsül antijenine göre 90 serotipe ayrılmasına karşın pnömokokal enfeksiyonların $\% 68-97$ 'sinden 12,14 ve 23 antijenlerini taşıyan serotipler sorumlu tutulmaktadır [16]. Bu patojenlere ek olarak, Capnocytophaga canimosus (köpek ve kedilerin ağız florasında bulunabilen Gram-negatif bir çomak olup, splenektomi sonrası gelişen sepsiste izole edilen klasik bir zoonoz etkenidir), Salmonella spp., Streptococcus suis, stafilokoklar ve diğer streptokok türleri etkenler arasında sayılabilir. Bununla birlikte, fulminan seyreden babeziyoz ile Plasmodium vivax ve Plasmodium malaria'nın etken olduğu sıtma olguları da bildirilmiştir [10,11].

$\mathrm{Bu}$ hasta grubunda enfeksiyonların yaşamı tehdit edici olabilmesi ve buna bağlı olarak hastanede yatış süresinin uzamasıyla birlikte kullanılan ilaçların ciddi ekonomik yük getirdiği düşünüldüğünde enfeksiyonların erken tanı ve tedavisinin yanı sıra hastaların eğitimi, aktif bağışıklanması ve kemoprofilaksisi önem kazanmaktadır. Ayrıca bu hastaların splenektomili olduğunu, bağışıklanma durumunu ve profilaktik antibiyotik kullanımını da içeren kişisel bilgilerinin bulunduğu tanımlayıcı kartlar taşımaları önerilmektedir [7-9]. Bu çalışma kapsamında da hastalar bilgilendirilmiş, eksik aşıları tamamlanmış ve tanımlayıcı aşı kartları verilerek sürekli yanlarında taşımaları önerilmiştir. Bu hastalarda profilaktik antibiyotik kullanımı, cerrahi öncesi cerrahi alan enfeksiyonlarına yönelik tek doz ya da maksimum 24 saat süreyle antibiyotik kullanımı veya splenektomize hastalar için uzun süreli kullanım şeklindedir. Bununla birlikte, splenektomi sonras1 antibiyotik profilaksisi çocuk yaş grubunda önerilirken, yetişkinlerde direnç gelişimi, hasta uyumu ve yan etki sorunları nedeniyle genellikle önerilmemektedir $[7,8]$. Bu çalışma grubundaki hastaların hiçbirine uzun süreli profilaksi yapılmamıştır.

Asplenik hasta grubuna üç temel aşı olan pnömokok, $H$. influenzae tip B ve meningokok aşıları mutlaka yapılması gerekmektedir. Ayrica bu hasta grubuna mevsimsel grip, tetanoz, suçiçeği ve kızamık-kızamıkçık-kabakulak aşılarını yaptırmaları tavsiye edilirken, risk durumuna göre hepatit B ve hepatit A aşıları da önerilmektedir [2]. Elektif koşullarda yapılan splenektomi ameliyatından iki hafta önce hastanın aşıları tamamlanmalıdır. Cerrahi öncesi aşı uygulanmamışsa, fonksiyonel antikor yanitının splenektomi sonrasi en erken iki hafta sonra oluşmasından dolayı aşı uygulamaları 14 . 
gün ve sonrasında yapılmalıdır [10]. Pnömokok aşısının beş yılda bir, meningokok aşısının 3-5 yılda bir ve mevsimsel grip aşısının her yıl yaptırılması önerilirken, $H$. influenzae tip B konjuge aşısının beş yılda bir uygulanması ile ilgili detaylı çalışmalar henüz yapılmamıştır [3,10]. Polisakkarit pnömokok aşısının içerdiği serotipler invazif enfeksiyon etkenlerinin \%85'ini kapsar ve aş1 uygulamasından 2-3 hafta sonra serotip spesifik antikor titresinde iki kat veya daha fazla artış saptanmaktadır [16]. Bu hasta grubunda aşının etkinliği \%60-91 arasında olduğu tespit edilmiştir [14]. Pnömokok aşısı, çalışma kapsamında değerlendirilen olguların \%62,7'sine operasyon öncesi, \%23,5'ine operasyon sonrası uygulanmışken, Görkem ve arkadaşlarının çalışmasında [9] olguların \%87,1'ine operasyon öncesi \%12,9'una operasyon sonrası, Özkören ve arkadaşlarının çalışmasında [8] olguların \%41'ine operasyon öncesi \%33,3'üne operasyon sonrası yapıldığı görülmüştür. Ayrıca pnömokok aşısı Kyaw ve arkadaşlarının çalışmasında [17] olguların \%88'ine uygulanmışken, bu oran Langley ve arkadaşlarının çalışmasında [18] \% 16,5 olarak belirlenmiştir. Ülkemizde yapılan çalışmalarda $H$. influenzae tip B konjuge aşısının ve meningokok aşısının uygulama oranları hakkında veriler bulunmazken, $H$. influenzae tip B konjuge aşısı sunulan çalışmada olguların \%72,6'sına, Kyaw ve arkadaşlarının çalışmasında [17] \%70'ine ve Langley ve arkadaşlarının çalışmasında [18] ise \%53,1'ine uygulanmıştır. Meningokok aşısı da bu çalışmada olguların \%72,6'sına uygulanmışken, Kyaw ve arkadaşlarının çalışmasında [17] \%51'ine uygulanmıştır. Aşılama oranları, çalışmalarda değişiklik göstermekle birlikte hem ülkemizde hem de yurt dışında yeterli düzeyde olmadığı görülmektedir.

Tüm Avrupa ülkelerini kapsayan bağımsız bir kuruluş olan Summit of Independent European Vaccination Experts (SIEVE)'in erişkin aşılama ile ilgili raporunda; aşılama oranlarının yükseltilmesi ve halkı daha etkin koruyabilme yolunun öncelikle bu konu ile ilgili hekimlerin ve sağlık personelinin tekrar bilgilendirilmeleri ile sağlanabileceği belirtilmektedir [1,19]. Çalışmamızda da görüldüğü gibi, diğer sağlık kuruluşlarından gelen hastalara yalnızca değişen sıklıkta pnömokok aşısı uygulanması ve diğer aşılar hakkında bilgilendirme yapılmaması, hem konu ile ilgili sağlık çalışanlarının ve hem de hastaların bu konudaki bilgi düzeylerinin yeterli olmadığını ve dolayısı ile erişkin aşılamada multidisipliner çalışmaların gerekliliğini ortaya koymaktadır.

\section{Kaynaklar}

1. Aşık Z, Çakmak T, Bilgili P. Erişkinlerin erişkinlik dönemi aşıları hakkındaki bilgi, tutum ve davranışları. Türk Aile Hek Derg 2013; 17: 113-8. doi: 10.2399/tahd.13.55265
2. Öztürk R. Erişkinde bağışıklama. Klinik Gelişim Derg 2012; 25: 49-59.

3. Eren ÖO, Sain Güven G, Akova M. Güncel bilgiler 1şığında erişkinlerde aşılama. Dahili Tıp Bilimleri Derg 2006; 13: 86-92.

4. Ergüven S. Dalağın enfeksiyon ve bağışıklıktaki rolü. Türk Hij Den Biyol Derg 1984; 1: 311-4.

5. Girgin S, Gedik E, Baç B, Taçyıldız Hİ. Benign hematolojik hastalıklarda splenektomi sonuçlarımız. Akademik Acil Tıp Derg 2008; 7: 42-5.

6. Akçay MN, Polat KY, Yıldırgan MI ve ark. Splenektomi sonrası gelişen infeksiyonlar. Ulus Travma Acil Cerrahi Derg 1995; 1: 67-70.

7. Arda B, Demirağ K, Işıkgöz Taşbakan M, Yamazhan T, Serter D. Splenektomiden 46 y1l sonra sepsis gelişen bir olgu nedeniyle splenektomi sonrası sepsis: Korunma ve öneriler. AKEM Derg 2004; 18: 180-3.

8. Özkören Çalık Ş, Pullukçu H, Işıkgöz Taşbakan M ve ark. Splenektomili hastaların pnömokok aşısı ile bağıșıklanma oranları ve diğer aşılar konusundaki bilgi düzeyleri. İnfeksiyon Derg 2007; 21: 71-4.

9. Görkem M, Atay MH, Kelkitli E ve ark. Hematoljik hastalıklarda splenektomi; tek merkez deneyimi. J Exp Clin Med 2012; 29: 276-9. doi: 10.5835/jecm.omu.29.04.005

10. Çağatay AA, Diz Küçükkaya R. Splenektomi sonrası sepsis. ANKEM Derg 2008; 22: 217-20.

11. Lutwick LI. Infections in asplenic patients. In: Mandell GL, Bennett JE Dolin R, editors. Mandell, Douglas, and Bennett's Principles and Practice of Infectious Diseases. 7th ed. Philadelphia: Churchil Livingstone Elsevier, 2010: 3865-73.

12. Moffett SL. Overwhelming postsplenectomy infection: managing patients at risk. JAAPA 2009; 22: 36-9.

13. Newland A, Provan D, Myint S. Preventing severe infection after splenectomy. BMJ 2005; 331: 417-8.

14. Bruni L, Bayas JM, Vilella A, Conesa A. Vaccination coverage in adults undergoing splenectomy: evaluation of hospital vaccination policies. Epidemiol Infect 2006; 134: 837-44. doi: 10.1017/S0950268805005704

15. Thomsen RW, Schoonen WM, Farkas DK, et al. Risk for hospital contact with infection in patients with splenectomy: a population-based cohort study. Ann Intern Med 2009; 151: 546-55.

16 Şengöz G, Yıldırım F, Kart Yaşar K ve ark. Splenektomili bir sistemik lupus eritematozuz hastasında aşıya rağmen gelişen pnömokok menenjiti. İnfeksiyon Derg 2007; 21: 153-6.

17. Kyaw MH, Holmes EM, Chalmers J, Jones IG, Campbell H. A survey of vaccine coverage and antibiotic prophylaxis in splenectomised patients in Scotland. J Clin Pathol 2002; 55 : 472-4.

18. Langley JM, Dodds L, Fell D, Langley GR. Pneumococcal and influenza immunization in asplenic persons: a retrospective population-based cohort study 1990-2002. BMC Infect Dis 2010; 10: 219. doi: 10.1186/1471-2334-10219

19. Vaughn JA, Miller RA. Update on immunization in adults. Am Fam Physician 2011; 84: 1015-20. 